\title{
Effects of timing of rumen energy supply on food intake in lactating dairy cows
}

\author{
P Faverdin, N Bareille
}

\section{INRA, Station de Recherches sur la Vache Laitière, Saint-Gilles, 35590 L'Hermitage, France}

Physical and metabolic signals play an important role in satiation in ruminants, but it is not known whether their effects depend on the time of their appearance relative to meals. The objective of this experiment was to compare the effects of energy supply to the rumen before or during a meal on dry matter intake (DMI) in dairy cows.

An energy supplement consisting of $4 \mathrm{~kg}$ of rolled wheat was introduced into the rumen for a period of $4 \mathrm{~h}$ either $4 \mathrm{~h}$ before $(W-4)$ or at the time (W0) of evening feed distribution and compared to indigestible controls (C-4 and $\mathrm{C}$ ) of similar initial wet volume ( $1.3 \mathrm{~kg}$ oak sawdust); the supplements were enclosed in 10 nylon bags $(60 \times 15$ $\mathrm{cm})$. Food intake response was recorded continuously during the experimental meal and the 3 following meals. Four fistulated dairy cows in midlactation ( $32 \mathrm{~kg}$ milk/d) were assigned to these 4 treatments on alternate days in a latin square design: 2 replications were used to measure feed intake and a third to control digestive and metabolic parameters. A mixed diet ( $70 \%$ maize silage, $30 \%$ concentrate) was offered ad libitum twice daily for $4 \mathrm{~h}(0700-1100$ and $1800-2200 \mathrm{~h})$.
DM disappearance from nylon bags was 1.24 and $1.35 \mathrm{~kg}$ for $W-4$ and $W 0$, respectively, and nil for sawdust (C-4 and $C 0$ ). Compared with (W-4) and (C-4), the presence of nylon bags during the first meal (WO and $\mathrm{C} 0$ ) decreased DMI in meal $1(-1.5 \mathrm{~kg} \mathrm{DM})$, with various compensatory effects in meal 2 or 3 and no remaining effects on meal 4 (table $\mathrm{I}$ ). In the control, DMI increased in meal 2 or 3 to compensate exactly for the decreased energy intake in meal 1. With energy supplementation, there was a further decrease in meal 2 or 3 which was far greater than the extra energy disappearing from the nylon bags. In contrast, energy supplementation before the meal did not significantly affect DMl either for the experimental meal or the others in spite of modifications to DMI kinetics.

In conclusion, the effect of rumen fill on food intake occurs directly whereas the effect of energy supply is delayed and probably requires integration of signals. Moreover, only energy supply synchronous to meals depresses DMI significantly.

Table l. Effect on food intake of rolled wheat or sawdust (control) in the rumen before or during a meal.

\begin{tabular}{lccccc} 
Intake $(\mathrm{kg} \mathrm{DM})$ & \multicolumn{2}{c}{ Control } & & \multicolumn{2}{c}{ Wheat } \\
\cline { 2 - 3 } \cline { 5 - 6 } \cline { 5 - 6 } & Before C-4 & During CO & & Before W-4 & During Wo \\
\hline Experimental meal & $11.8^{\mathrm{a}}$ & $10.2^{\mathrm{b}}$ & & $11.7^{\mathrm{a}}$ & $10.9 \mathrm{~b}$ \\
2 following meals & $21.9^{\mathrm{a}}$ & $23.3^{\mathrm{b}}$ & & $21.4^{\mathrm{a}}$ & $19.0^{\mathrm{C}}$ \\
Total intake & $33.7^{\mathrm{a}}$ & $33.5^{\mathrm{a}}$ & & $33.1^{\mathrm{a}}$ & $29.9^{\mathrm{b}}$ \\
\hline
\end{tabular}

Means with different letters $a, b, c$ are significantly different at $P<0.05$. 